\title{
K problematiki palatalizacije velarov v stari frizijščini
}

\author{
Luka Repanšek
}

Cobiss 1.01

Opdroegen oan Rolf H. Bremmer, jr., myn learaar Aldfrysk

Osnovni namen članka je celostna predstavitev starofrizijske palatalizacije podedovanih velarov $* k,{ }^{*} g$ in $* \gamma$, pri čemer se posebna pozornost posveča problematičnim mestom, ki izkazujejo njen izostanek.

Ključne besede: stara frizijščina, stara angleščina, palatalizacija

\section{Remarks on the palatalization of velars in Old Frisian}

This paper provides a comprehensive account of Old Frisian palatalization of the inherited velars $* k,{ }^{*} g$, and $* \gamma$. In addition, it addresses the specific problem of the frequent failure of velars to palatalize.

Key words: Old Frisian, Old English, palatalization

\section{Uvod}

Na podlagi posameznih narečij stare frizijščine in sodobne severne otoške frizijščine je na prafrizijsko obdobje mogoče projicirati obstoj vsaj treh palatalov: ${ }^{*} c,{ }_{3}$ in $* j$. Od teh sta prva dva najverjetneje že v starofrizijskem obdobju razpadla v dvofonemski zaporedji /ts/ ter /dz/, ki se v sodobni frizijščini odražata poenostavljeni v /s/ oz. /z/ ali /d/, v prvem primeru zahodna frizijščina ohranja tudi afrikato ${ }^{1}$ (odvisno tudi od pozicije znotraj besede; prim. sat. setel 'kotel', zfriz. tsjettel 'isto' stfriz. tsetel, zfriz. brutsen 'zlomljen' $\sim$ stfriz. britsen, zfriz. lizze 'ležati', sfriz. lade 'isto' $\sim$ stfriz. lidza). Zapisovalni uzus v starofrizijskih virih ni ustaljen: /ts/ dobimo zapisan kot $\langle$ sz, ts, tz, z, st, sth, zt, th, thz, sk $\rangle$, /dz/ kot $\langle\mathrm{dz}, \mathrm{ds}, \mathrm{dsz}, \mathrm{z}, \mathrm{zi}, \mathrm{s}\rangle, / \mathrm{j} / \operatorname{kot}\langle\mathrm{i}, \mathrm{j}\rangle$, $\mathrm{v}$ vzglasju $\langle\mathrm{i}, \mathrm{j}, \mathrm{g}\rangle{ }^{2}{ }^{2}$ Tako di- kot monografi so lahko opremljeni z najverjetneje le pisnim $\langle i\rangle$ (thindz(i)a 'zdeti se', rēts(i)a 'seči'). Pfriz. *c in ${ }^{*} 3$ sta preko asibilacije palataliziranih $* k$ ' in $* g$ ' nastala iz pgerm. $* k$ ter $* g$, pri čemer se je zveneči velar

1 Refleks /ts/v sodobni zahodni frizijščini, tj. /tsj/, je v slovnicah obravnavan kot fonemsko zaporedje!

2 V članku bodo uporabljeni standardizirani zapisi s $\langle\mathrm{ts}\rangle \mathrm{za} / \mathrm{ts} /,\langle\mathrm{dz}\rangle \mathrm{za} / \mathrm{dz} /$ ter $\langle\mathrm{i}\rangle$ oz. $\langle\mathrm{j}\rangle$ (na besednem vzglasju) za $/ \mathrm{j} /$. 
$-\quad\left(<\right.$ pide. $\left.{ }^{*} g^{h}, k\right)$ vsaj v stari frizijščini (ter stari angleščini) $)^{3}$ kot zapornik ohranil le v položaju za nazalom $\left({ }^{*} \eta g\right)$ in $\mathrm{v}$ geminati $* g g<$ pgerm. ${ }^{*} g$ pred $* j$. V ostalih položajih torej refleksa palataliziranega *g'v stari frizijščini ne pričakujemo, pač pa je na teh mestih pričakovan refleks palataliziranega zvenečega velarnega pripornika $* \gamma$, ki je že zgodaj sovpadel z /j/ < pgerm. ${ }^{*} j$ (prim. zamenljiva grafema v stfriz. ge $\bar{e} r \sim$

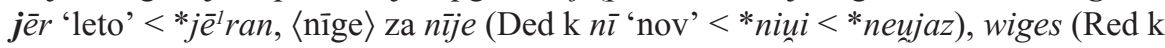
wei 'pot') $=$ weies $<*$ ueræs $)$.

Zanesljivih znakov o palatalizaciji nezvenečega velarnega pripornika $|\chi|<$ pgerm. ${ }^{*} \chi$ v predkonzonantnem položaju in v izglasju ni. Glagolska oblika siucht

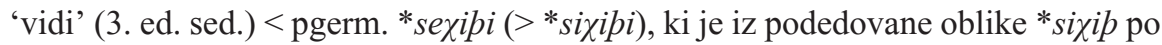
sinkopi nastala $\mathrm{z}$ lomitvijo sprednjega $i$ v položaju pred pokritim velarnim pripornikom (i > iu, io / $\quad \chi C$ ), je lahko zavajajoča, saj je bil nezveneči velarni pripornik po lenizaciji medglasnega $* \chi>$ pfriz. ${ }^{*} h$ analoško restituiran. ${ }^{4}$ Njegova kvaliteta vsekakor ni bila palatalna, saj do lomljenja prihaja le v izrazito velarnem okolju (prim. stfriz. kniucht 'sluga' $<* k n e \chi t a z$, fiuchta 'bojevati se' $<*$ fextanan). Ijevska

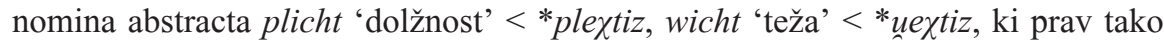
ne izkazujejo lomljenja (**pliucht, **wiucht), sicer kažejo na palatalno kvaliteto soglasniške skupine, ki je lahko posledica sledečega sprednjega $* i$, vendar gre v tem primeru najverjetneje za regresivno asimilacijo. ${ }^{5}$

Pri obravnavi starofrizijske in staroangleške palatalizacije velarov se ne upošteva terminološko razlikovanje med palatalizacijo in jotacijo, ${ }^{6}$ saj gre znotrajsistemsko v primerih, ko je povzročitelj palatalizacije sledeči $* j$, za identičen proces kot v primerih, ko je povzročitelj sprednji samoglasnik. V primeru *j namreč ne prihaja do absorpcije povzročitelja fonetične spremembe, temveč je $* j$ enako kot *i pozneje podvržen sinkopi.

3 Enotnega mnenja o tem, ali je bil pgerm. zveneči velar pripornik ali je prešel v zaporniško vrsto, ni. Na podlagi sodobne zahodne frizijščine, v kateri je distribucija zvenečega velarnega pripornika omejena na medglasje, se sklepa, da je bilo stanje v stari frizijščini enako in da gre za arhaizem. Vendar je pri tem treba upoštevati dejstvo, da tudi srednja angleščina (oz. že pozna stara angleščina) v vzglasju pozna le zaporniško artikulacijo, a je na staroangleško stanje vendarle treba projicirati priporniško. Glede na dejstvo, da je refleks palataliziranega vzglasnega zvenečega velara $v$ stari frizijščini vselej *j, je verjetneje, da je vsaj še za prafrizijsko obdobje treba predpostaviti priporniško $\operatorname{artikulacijo} * \gamma$.

4 Lenizacijo medglasnega $* \chi$ je treba predpostaviti na podlagi kontrahiranih oblik tipa sia 'videti' < *se-an <*sehan < pgerm. *se $\chi^{\prime \prime}$ anan.

5 Za raziskovanje uporabni pragermanski glagol *hlaxjanan 'smejati se' se v frizijščini ne ohranja in torej obnašanja $* \chi$ pred $* j$ ni mogoče z gotovostjo predvideti. V stari angleščini je skupina vsaj v času lomljenja še velarna, stang. hlehhan/hlihhan 'smejati se' $<$ (preglas)

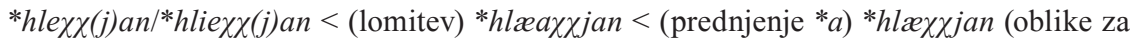
poševnico so zahodnosaške).

${ }^{6} \mathrm{~V}$ primerjavi s slovanščino, kjer je to potrebno, saj jotacija in palatalizacija nista $\mathrm{v}$ neposredni povezavi, temveč je jotacijo treba razumeti v kontekstu zakona odprtega zloga (v slovanščini v primeru $* j$ namreč vedno pride do absorpcije). 


\section{$1 \quad$ Palatalizacija v vzglasju}

Nezveneči velarni zapornik $* k$ je palataliziran pred vsemi sprednjimi samoglasniki (tudi če so prvi del diftongov), ki so v jeziku obstajali po procesu ustalitve pgerm. $* \bar{e}^{1}$ v poziciji sprednjega odprtega $* \bar{x}$ ter vzporednem prednjenju kratkega $* a>* x$ : stfriz. tsīvia 'prepirati se' < kīōjanan, tsīve 'prepir', tserl 'mož' <*k'erl, *tsin' *'brada' <*k'innu <*ken(n)uz, tsiāke 'lice' <*k'eukæx, tsīze $e^{8}$ 'sir' <*k' $\bar{x} s \bar{\imath} \leftarrow$ lat. cāseus, tsetel 'kotel' $<* k$ 'æetil $<* k a t i l a z \leftarrow$ lat. catillus (stang. cytel) ${ }^{9}$, tser(e)ke $e^{10}$ 'cerkev' <*k'irikæ <*kirikōn (stang. ciricie), tselk 'kelih, čaša' $<* k$ 'ælik $\leftarrow$ lat. calicem (stang. ćelc̀). Vzporedna oblika kiāsa 'izbrati' k tsiāza 'isto' $<* k$ 'eusan 'isto' ima refleks nepalataliziranega velara najverjetneje analoško uveden po oblikah, v katerih je $* k$ stal v okolju, kjer do palatalizacije ni prišlo, npr. 3. ed. pret. $k a \bar{s}<* k a u s, \mathrm{mn}$. pret. keren $\leq * k u r u n,{ }^{11}$ pret. del. *kurina- > keren (AFG $\S 133$ ). Podobno velja za stfriz. kerva (3. ed. sed. kerft) 'rezati' za pričakovano **tserva, **tserft (stang. ceorfan, cearf) <*kerbanan, *karb po mn. pret. *kurvun in pret. del. korven, $\mathrm{k}$ čemur prim. identično stanje v srang. kerven, ang. carve/'ka:v/ $\leftarrow$ stang. curfon, gecorfen).

Ob možnosti, da je $i$ v zapisu tsiāza grafični in gre pravzaprav za obliko [cāza], se pojavlja vprašanje, ali ni povzročitelj palatalizacije v tem primeru morda *j, in s tem tudi vprašanje medsebojne relativnokronološke umestitve palatalizacije in internofrizijskega razvoja pgerm. diftonga $* e u$. Vendar je prav na podlagi analoške oblike kiāsa mogoče sklepati, da je palatalizacija * $k$ še iz časa pred prehodom padajočega diftonga $* e u>* e o \mathrm{v}$ rastoči diftong $* j \bar{a}$ (preko io, ia po naraščajoči disimilaciji), saj bi v nasprotnem primeru po analoški zamenjavi $* c \mathrm{~s} * k$ pričakovali obliko **kāsa. ${ }^{12}$

Odsotnost palatalizacije v stfriz. $k \bar{l}$ (Imn h $k \bar{u}$ 'krava') <*küiz, kētha 'naznaniti' < *kȳpan < smgerm. *kūpjan < *kunpjanan, kening 'kralj' <*kyning < *kuningaz, ${ }^{13}$ kest 'izbira' < *kustiz, *kerf 'rez' <*kurbiz, *kenep 'brki' <*kunipaz, kessa 'poljubiti' <*kussjanan, kēla '(o)hladiti' <*kōljanan, ken 'rod, sorodstvo' <

7 V tsinbaka 'lice'.

8 Pričakovana oblika je sicer $* * t s e \bar{z} e$, pri čemer zaprti refleks za pfriz. * $\bar{x}$ na tem mestu ni razložljiv po fonetični poti. Stang. $\dot{c} \bar{l} s e<\dot{c} \bar{y} s e$ je drugačnega nastanka, saj je zaprti monoftongični refleks sekundarno nastal iz preglašenega /æa/, tj. /ie/, $<* \bar{x}$ po procesu diftongizacije za palatalom (ang. "palatal diphthongization«). Stara frizijščina diftongizacije $\mathrm{v}$ položaju za palatalom ne pozna.

$9<$ (preglas) ${ }^{*}$ cietel $<$ (diftongizacija v položaju za palatalom) ${ }^{\prime}$ čæatil $<* k ' æ x t i l$.

${ }^{10}$ Oblika je riustrinško- in zahodnofrizijska, medtem ko je $v$ emski frizijščini izpričana oblika tsiurke z lomljenim $i$ (Stiles 1995: 214).

${ }^{11}$ Korenski vokalizem mn. pret. je $\mathrm{v}$ drugem krepkem razredu pogosto zamenjan $\mathrm{z}$ vokalizmom, prisotnim v preteklem deležniku (Bremmer 2009: § 132).

${ }^{12}$ Zfriz. oblika kieze [kiaze] je tako kot biede 'ponuditi' < stfriz. biāda nastala po absorpciji $j$ v izhodiščni obliki *kjiaze $<* k j \bar{x} z e<* k j \bar{a} z a$ (Hoekstra 2001: 728).

${ }^{13}$ Pfriz. $* \breve{y}>/ \check{\bar{e}} /($ v zahodni in emski vzhodni stari frizijščini) in $* \breve{y}>/ \overline{\mathbf{1}} /$ (v vezerski vzhodni in severni otoški frizijščini); pfriz. $* \check{\bar{\varnothing}}>/ \overline{\overline{\mathrm{e}}} /$. 
*kunjan kaže, da je bil proces zaključen že najpozneje do razokroženja samoglasnikov, ki so nastali po ijevskem preglasu, v sprednja $\check{\bar{e}}$ oz. $\breve{\bar{l}}$.

Prav tako je palatalizacija odsotna pred pfriz. $* \bar{x}<* a i, * a i{ }^{i}$, ki je po monoftongizaciji nastal po zaključenem delovanju ijevskega preglasa: kēi 'ključ' $<$ $k \bar{x} j u<* k a i j \bar{o}$ (stang. $c \bar{x} \dot{g}) \cdot{ }^{14}$

V primeru zvenečega velarnega pripornika je stanje identično: jeft 'dar, pri-

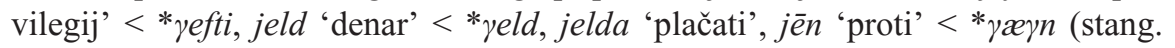

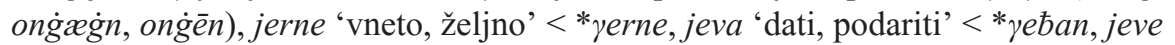

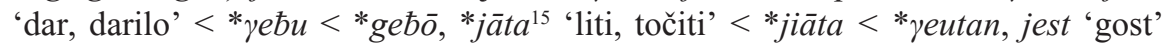
$<*$ yæsti $<*$ gastiz. Do regularnega izostanka ponovno prihaja pred preglašenimi samoglasniki ter monoftongičnim refleksom *ai, *aii: stfriz. gerdel 'pas' < *gurdil,

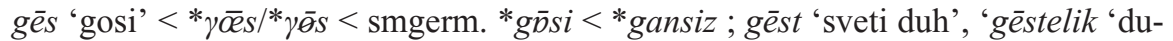
hoven' $<* \gamma \bar{x} s t-<*$ gaist-, gēia 'pokoriti se' $<* \gamma \bar{x}$ jja $<$ *gaigjanan, *gēr 16 'sulica' $<* \gamma \bar{x} r<*$ gaizaz. Na podlagi stfriz. gers 'trava' < *yræes < pgerm. *grasan (prim. stang. gærs) je mogoče nadalje sklepati, da je palatalizacija starejša tudi od metateze tipa $r \breve{V}>\breve{V} r /$ $n, s$.

Do fonemizacije in s tem posledično asibilacije palatalov je v primeru * $\gamma^{\prime}$ najverjetneje prišlo že zgodaj, in sicer preko sovpada * $\gamma^{\prime}$ s starim $* j,{ }^{*} k$ ' pa je bil fonemiziran, ko njegova alofonska distribucija ni bila več predvidljiva, tj. po monoftongizaciji *ai (tip kēi). V času vstopa monoftongičnih refleksov *ai, tj. /ā/ ter $/ \overline{\mathfrak{x}} /$, v dolgovokalni sistem še lahko govorimo o prafrizijščini, čeprav je morala biti $\mathrm{v}$ tem času že rahlo notranje diferencirana, saj posledice pojavitve novih dolgih samoglasnikov za sprednjo samoglasniško vrsto niso več splošnofrizijske.

\section{$2 \quad$ Palatalizacija v medglasju}

Za primere s palatalizacijo v medglasnem položaju štejejo vse oblike, kjer velar prvotno ni stal v stiku s premorom (tj. v absolutnem izglasju), torej tudi oblike, nastale

${ }^{14}$ Pri stfriz. kind 'otrok' gre za izposojenko iz stare visoke nemščine (verjetno preko stare saščine) po obdobju zaključene palatalizacije, saj bi se pgerm. *kenpan $<{ }^{*} g$ ' $[e ́] n H_{l}-t o-$ (vrddhirani pide. ${ }^{*} g^{\prime} \eta_{0} H_{1}$-tó-) razvilo v pfriz. ${ }^{* *} \operatorname{cin} p>$ stfriz. ${ }^{* *} t \operatorname{sinth}$, prim. stfriz. 3. ed. pret. warth : stvn. ward $<*$ ward $<*$ warp. Domači podedovani leksem je sicer bern $<$ *bærn < *barnan (stang. bearn, got., stisl., stsaš., stvn. barn).

${ }^{15}$ Ohranjeno v ütjāta 'prelivati, polivati' in bijāta 'zalivati' (AFW: 47, 558).

${ }^{16}$ Ni mogoče predvideti, kolikšne odprtosti je bil pfriz. zadnji zaokroženi samoglasnik (nastal po sovpadu smgerm. * $\tilde{\bar{a}}<* a \eta \chi, * a m f, * a n s, * a n p$ in $* \bar{e}^{l}$ pred nazalom) v času ijevskega preglasa. Če je do časa slednje spremembe že popolnoma sovpadel s starim $* \bar{o}$ $\left(<\right.$ pgerm. $\left.{ }^{*} \bar{O}\right)$, je bil preglašeni samoglasnik zaprti zaokroženi ${ }^{*} \bar{\theta}$, ki je sovpadel z $* \bar{\theta}<$ $* \bar{o}^{i}$, v primeru, da je bil $* \bar{p}$ v času, ko je nastopil ijevski preglas, ujet na pol poti, torej v fazi polodprtega zadnjega zaokroženega $* \bar{\jmath}$, pa je ustreznejša rekonstrukcija preglašenega samoglasnika $* \bar{\alpha}$ (takšno je stanje v stari angleščini, prim. stang. bræm(b)el 'robida' $\leftarrow$ (zgodnje skrajšanje) *bræ̌mblas $<$ *brōmilas < *brōmilas (Hogg 1992: 126-127)). V obeh primerih v starofrizijskem obdobju pričakujemo razokroženje v/ê/, kar je možno zaključiti na podlagi *baurijan $>*$ bējan $>$ stfriz. bēia 'upogibati'. 
po poznem odpadu izglasnega elementa, ki je še povzročil preglas, saj se ti primeri razlikujejo od tipa stfriz. dei 'dan', kjer je bila apokopa izglasja zgodnja (zgerm.) in

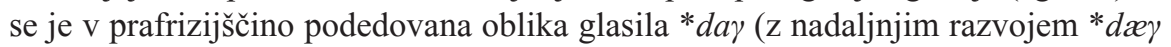
$>* d æ j>d e i)$. Novi glasovni okolji, ki postaneta relevantni v obravnavanem položaju, sta velar v položaju pred $*_{j}$ in zveneči velarni zapornik (vselej za nosnikom in v geminati) pred sprednjim samoglasnikom oz. ${ }^{*} j$. V stiku s $* k$ oz. ${ }^{*} g$ z $* j$ v zahodni germanščini pride do podvojitve, s čimer se odpravi ambisilabičnost soglasnika $\mathrm{v}$ stiku z drsnikom (Hock 1991: 138). V primeru nastalega zaporedja *kk' oz. *gg' sicer po regresivni asimilaciji pričakujemo nastanek zaporedij * $k$ ' $k$ ' oz. * $g$ 'g', prim. stang. $\langle\mathrm{cc}\rangle[\check{c} \mathrm{c}]$ oz. $\langle\mathrm{cg}\rangle\left[\check{\zeta}_{3}\right]^{17}<* k^{\prime} k^{\prime}<* k k j$ oz. ${ }^{\prime} g^{\prime} g^{\prime}<* g g j$, vendar v frizijščini obstoj dolgih palatalov ni nikjer dokazljiv, to pa najverjetneje zato, ker so asibilirani palatali v obdobju stare frizijščine že razpadli v dvofonemska zaporedja (prim.

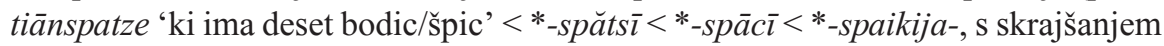
pred sledečo dvokonzonanco $).{ }^{18}$

Do palatalizacije $* k$ in $* g$ regularno prihaja pred $*_{i},{ }^{*} \bar{l}$ in $* j$ : stfriz. bi-tetsa 'polastiti se' <*-tukkjan <*-tukjanan, litsa '(iz)ravnati' < *likijanan, bletsa 'pokazati' (za pričakovano **blētsa) <*blaikijanan, bretse 'zlom' <*brukiz, wìtsing $\leftarrow$ stisl. viking, lètsa 'zdravnik' <*lēe kijaz, thretsa 'pritiskati, stiskati' <* prukkjan $<*$ prukjanan, hemmertse 'občinsko zemljišče' <*-markijan, hlentsene 'vdrtina, krivina po poškodbi' $\leq *$ hlænkīn, ètsen 'hrastov' $<* \bar{e} k$ '̄̄n $<*$ aikinna-, letsen $<* l u$ kina- (pret. del. k lūka 'zakleniti'), bretsen <*brukina- (pret. del. k breka 'zlomiti'), ritsen <*rukina- (pret. del. k reka 'prekriti s pepelom'), spritsen <*sprukina- (pret. del. k spreka 'govoriti'), stetsen < *stukina- (pret. del. k steka 'nabosti'), batsen < *bakina- (pret. del. k baka 'peči'), hwendzen <* zaygina- (pret. del. k hwā'viseti'), ${ }^{19}$ ledza 'položiti' < *laggjan < *lagjanan, lidza 'ležati' <*liggjan < *ligjanan, sedza 'reči' < *saggjan < *sagjanan, swendza 'zalučati, vreči' < *suaggüijanan, lendze 'dolžina' $\leq$ *leygīn.

Do izostanka palatalizacije regularno prihaja pred preostalimi sprednjimi samoglasniki, kakor je nedvoumno razvidno iz optativnih oblik kot 3. ed. opt. sed. blīke (k blīkan 'biti viden'), breke (k breka 'zlomiti'), brenge (k brendza 'prinesti') $<*_{-} \bar{x}<*_{-} a i-$, imenovalniških edninskih oblik ženske nosniške sklanjatve, npr. tun-

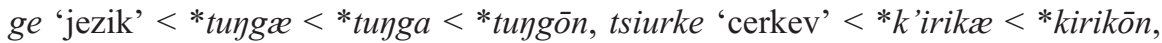
adverbialnih izpeljank tipa lange/longe 'dolgo' (stang. lange) $<*$ longe $<*$ langẽ d, adverbialnega sufiksa -līke (stang. -līce) < -līkẽ d (npr. riuchtlīke 'zakonito') ipd. Iz naštetega sledi, da so morale dvojnične edninske dajalniške oblike betse $\sim$ beke (Ded k bek 'hrbet' < *bakaz), thinge thindze (Ded k thing 'stvar; zborovanje; sodišče' <* pengaz), keninge kenindze (Ded h kening 'kralj' $<*$ kuningaz) nastati po sinkretizmu prvotnega dajalnika $* b æ k æ x<$ brk $\bar{x}<* b a k a i<*-\bar{i} i$ in mestnika

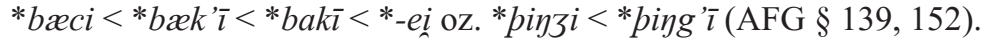

Tudi v medglasju palatalizacija regularno izostaja pred razokroženimi sprednjimi samoglasniki, nastalimi po ijevskem preglasu, prim. makia 'narediti' <

\footnotetext{
$17 \mathrm{~V}$ etgēr 'sulica'.

${ }^{18} \mathrm{~S}$ fonetičnimi simboli sistema IPA točneje [cc] oz. [ff].

${ }^{19}$ Prim. stfriz. lat 'vodil je' $<* l a t t<* l \breve{x} d p<* l \bar{x} d i p<* l a i ð i p i($ de Vaan 2011: 309).
} 
- * *makija $<*$ makeja $<$ makēja $<$ *makōjanan (stang. makian), frēgia 'spraševati' <

퍼 *frēelgōjan(an) (= stsaš. frāgon), folgia 'slediti' <*fulgōjan(an). ${ }^{20}$

$\mathrm{V}$ vzporednih preteklih deležnikih breken 'zlomljen', bi-leken 'zaklenjen' je bil velar restituiran po interparadigmatskih oblikah, kjer je bil regularen, npr. po infinitivu. Dvojnične oblike nekaterih preteklih deležnikov, ki izkazujejo tako odsotnost palatalizacije kakor tudi odsotnost preglašenega korenskega samoglasnika, pa so najverjetneje odraz vzporednih deležniških oblik s pgerm. sufiksom *-an-a(stang. -en), ki je v frizijščini sicer večinoma izpodrinjen s konkurenčnim sufiksom *-en-a- $>*_{-i n-a-.}$ Ob teh oblikah se pojavljajo tudi že znane z odsotnostjo palatalizacije, vendar s prisotnostjo preglasa, ki so nastale po interparadigmatskih izravnavah korenskega konzonantizma. Tako gendzen < *gangina- (pret. del. k gunga 'iti') ob gangen $<*$-ana-, gengen $(\leftarrow 3$. ed. pret. gēng), fendzen $<*$ faygina- (pret. del. $\mathrm{k}$ $f \bar{a}$ ' ujeti') ob fangen, fengen ( $\leftarrow 3$. ed. pret. fêng).

Nedoločniške oblike glagolov prve šibke vrste (sem večinoma spadajo kavzativi s strukturo pgerm. ${ }^{*} C a C$-ji $/ a^{21}$ oz. ${ }^{*} C \bar{o} C / C a C C$-iji/a-), kjer je palatalizacija $* k$ in $* g$ pričakovana, saj se vsakokrat pojavljata $\mathrm{v}$ položaju pred $* j$ oz. $*_{i}\left(\mathrm{v} *_{-} i j-\right)$, se večinoma pojavljajo tako $\mathrm{z}$ odrazom palataliziranega kot nepala-

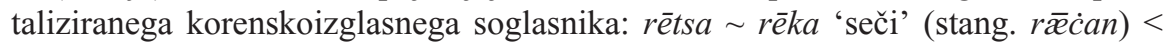
* raikijanan, sentsa senka 'potopiti' (stang. sencian) < *saykijanan (proti sinka, stang. sincan 'potoniti' < *siyk-i/a-), thentsa thenka 'misliti' (stang. pencian) < * paykijanan, sētsa sēka 'iskati' (stang. sēcan) < *sōkijanan, brendza brenga 'prinesti' (stang. brengan) < *braygijanan (ob krepkem bringa < *breyg-i/a-), sindza senga 'osmoditi' (sengan) < *saygijanan, dītsa dīka 'graditi nasipe' < *dīkijan(an), skentsa skenka 'nalivati' <*skaykijanan (stang. scienċan), wertsa $\sim$ werka $\sim$ wirtsia $\sim$ werkia $<$ *uurkijanan (stang. wyrćan). ${ }^{22}$ Podobno stanje je mogoče opazovati v srednji angleščini, kjer se penchen 'misliti' < stang. pencian pojavlja ob penken, pinchen 'zdeti se' ob pinken < stang. pyncian, sēchen 'iskati' < stang. sēंan ob sēken, wirchen 'delati' < stang. wyrćan ob wirken itd. (MEG $\S 282,285)$. Kot pričajo srang. bȳen 'kupiti', seien 'reči', leien 'položiti' < stang.

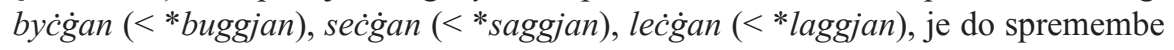
v konzonantizmu moralo priti preko naslonitve na interparadigmatske oblike, kjer takšna odstopanja pričakujemo po glasovnem razvoju. Izostanek podvojitve je v tem tipu pričakovan le v 2. in 3. ed. sed. ter 2. ed. imp., kjer je že zgodaj prišlo do absorpcije $*_{j}$ v sledeči $*_{i}$ (pide. $*_{-} i e->$ pgerm. $*_{-j i-}>*_{-} i-$ ) oziroma do kontrakcije

${ }^{20}$ Za pričakovano **hendzen po nedoločniku $h w \bar{a}$ 'viseti' $<* h u \bar{a}<*$ hōan $<*$ hōhan (AFG

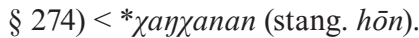

${ }^{21} \mathrm{~V}$ sodobni zahodni frizijščini je pri podedovanih nedoločnikih druge šibke vrste prišlo do t. i. druge (zahodnofrizijske) palatalizacije, saj je po prehodu izglasnega -ia $(>-i e) \mathrm{v}-j e$ nepalatalizirani velar spet prišel v stik z $j$, kar je sprožilo nastanek srednjezahodnofrizijskih oblik tipa meitse $<*$ meikje $<$ stfriz. makia, ki se $\mathrm{z}$ analoško restituiranim $-j$ - ohranjajo kot zfriz. meitsje, laitsje 'smejati se' < stfriz. hlakkia 'isto', weitsje 'paziti' < stfriz. wakia 'bedeti; paziti' ipd. (Hoekstra 2001: 729).

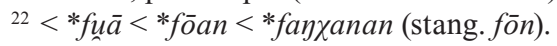


pgerm. $*_{-} i j i->*_{-} i{ }^{\prime} i->*_{-}-\overline{-}$, v primeru 2. ed. imp. pa je po zgodnji apokopi izglasnega $*_{-} e<$ pide. $*_{-} e$ korenskoizglasni soglasnik stal pred ozloženim $*_{-i}<*_{-j}$ oz. pred

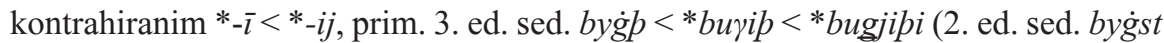

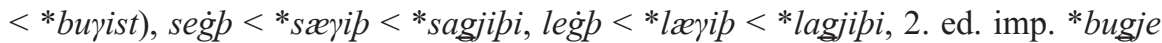

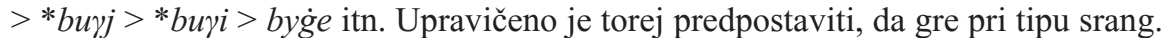
wirchen $\sim$ wirken oz. stfriz. wertsa $\sim$ werka za identičen analoški proces, vendar se pri tem postavlja vprašanje, zakaj v primeru, ko gre za zapornika $* k$ in $* g$, v relevantnih oblikah ni prišlo do palatalizacije. Ob regularnem poteku razvoja 3. ed. sed. *uurkijipi $>*$ uurkī $p>* u y r k$ '̄ $p$ bi po sinkopi ${ }^{23}$ pričakovali asibilacijo palatala, torej stang. (zsaš.) **wyrćp oz. stfriz. **werts $p$, vendar je očitno v takšnem primeru vselej prišlo do njenega izostanka, kar je razložljivo s pozicijsko fonetiko. Tu je na mestu van Heltnova pripomba, da do takšnega razvoja pride »[...] weil die Syncope des $i$ der End.[ung] -ith älter ist als die Entwicklung der Assibilierung« (AFG § 134, podčrtal L. R.), saj je bilo pred sinkopo glasovno okolje še nedotaknjeno in do polarizacije še ni prišlo. V trenutku nastopa sinkope pa je palatalizirani velarni zapornik trčil s soglasnikom, kar je preprečilo njegovo nadaljnjo asibilacijo: ${ }^{24}$ palatalizacija *uyrk'ip > sinkopa *uyrk'b> depalatalizacija *uyrkp (stang. (zsaš.) ${ }^{25}$ wyrcp, enako wyrcst itd.). Dejansko izpričane starofrizijske oblike z zaporedji $-c t h /-k t h,-c h t,-c$, -keth oz. -xt (=-kst) in -gt, -g, -ck, -kth, -cht, -ch, -geth oz. -gest takšno domnevo nedvomno potrjujejo: sēkth, secht oz. sēxt; brencht, breng, brenck, branght, brengeth oz. brengest; scenc; wercth. Kot kaže 3. ed. sed. sprecht 'govori' (ob sprekth), je do prehoda $-k p \mathrm{v}-\chi t$ prišlo pozno, saj bi sicer pričakovali lomitev (** spriucht). ${ }^{26}$ Tematski samoglasnik v tipu brengeth/st je treba razumeti kot sekundaren, saj bi se oblika z ohranitvijo - $i$ - glasila **brendzeth/st. V primeru velarnega zapornika so oblike $\mathrm{s} * k$ in $* g$ (le v zaporedju *- $\eta g-$ ) možne le v 2./3. ed. sed., saj sta se velara pred $*_{-} i$ oz. $*_{-}-*_{-}(i) j e$ seveda lahko regularno palatalizirala. Prav tako niso relevantne preteritne oblike navedenih šibkih glagolov, pri katerih je sinkopa $i$ v notranjem odprtem zlogu sicer pričakovana, saj v primeru zvenečega velara pred ${ }^{*} i$ ne bi prišlo do podvojitve $\left(*-\gamma-i\right.$-ðæ $\left.>*_{-j-j e}\right)$, večina navedenih glagolov s korenskoizglasnim nezvenečim velarnim zapornikom pa preteritalne oblike tvori brez tematskega samoglasnika in je do prehoda velarnega zapornika v nezveneči velarni pripornik * $\chi$ prišlo že pred razvojem palatalizacije (rachte, thochte, sochte, brochte, wrochte $<$

${ }^{23}$ Po sistemski odpravi tipa *CaC-iji/a-<*Coc-éielo-, ki je že pragermanska.

${ }^{24}$ Stfriz. wirts(i)a, stang. wyrćan, stsaš. wirkian, stvn. wurchen (stfrank. wirken), got. waúrkjan < *uurkjanan (I. šibka vrsta), stfriz. werkia < *uerkōjanan (II. šibka vrsta) (stsaš. werkon, stvn. werkōn). Oblike s korenskim $i$ so zahodnofrizijske, prim. stzfriz. wirda < wertha 'postati', wird < werd 'beseda' itn. (Bremmer 2009: § 208).

${ }^{25}$ Stfriz. rìtsa/e 'bogastvo' dokazuje, da je palatalizacija nedvomno starejša od sinkope, saj *rīk-ij-u> palatalizacija *rīk'-ij-u> sinkopa *rīk'-u>rīcu (> stfriz. rītse/a) in ne **rīk$i j-u>* * i \bar{i} k u$.

${ }^{26}$ Dodatno se takšen pozicijski razvoj palatalov morda potrjuje v sinkopiranih oblikah Imn fingrar ter anglar, po katerih bi prišlo do analoškega vnosa neasibiliranega velara v nesinkopirani obliki finger 'prst' < *fengraz ter angel/engel 'angel' < *aygilaz (AFG: 247) (prim. stang. engel (ang. /'eındłl//) vendar ang. /'fıngə/ (stang. finger ?)). 


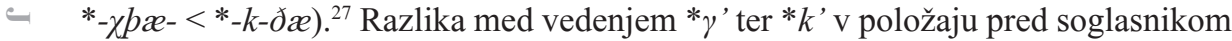
je razložljiva, če predpostavimo, da je $*_{\gamma}$ ob stiku s sprednjim samoglasnikom oz. ${ }^{*} j$ takoj sovpadel $\mathrm{z} * j$ in tako ni bil več v (morfofonemsko tvornem) alofonskem razmerju $\mathrm{Z} * \gamma \cdot{ }^{28}$

Posebno problematiko predstavlja prisotnost oblik z neasibiliranimi velari $\mathrm{v}$ paradigmah samostalnikov, katerih sufiksalni del se je pričenjal na $*_{-j}$ - (tj. pri ja- in jō-osnovah): widze $\sim$ wegk 'konj' < *uegjan, Ded widze $\sim$ wegke (stang. wic̀g); hreg 'hrbet' <*hrugjaz, Red reggis (stang. hryc் $\dot{\text { ) }}$ ) egg(e) edze 'rob; rezilo meča; meč' $<* a g j \bar{o}$, Ded egge, Dmn eggum (stang. ec $\dot{g}$ ); bregge (in ne **bredze kot npr. edze) 'most' <*brugjō (stang. briç $\dot{\text { ) }}$. Van Heltnovo razlago, ki temelji na predpostavki, da je do podvojitve velara pred $*_{-j}$ - prišlo že pred zgodnjo apokopo $\left(*_{-}-K-j a z / n>\right.$ podvojitev $*_{-} K K-j a / \tilde{a}>$ apokopa $\left.*_{-} K K j\right)$, je treba zavrniti, saj je iz stvn. beti/peti 'postelja' < *badjan, weti 'zastavilo' < *uadjan z negeminatnim zapisom (Braune 1987: $§ 201^{4}$ ) ob običajnem betti (kot nezzi $<*$ natjan, kunni $<*$ kunjan itd.) ter starofrizijskega arhaizma fene 'pašnik' < *fanja- (= stsaš. feni 'močvirje' (Krogh 1996: 292-293)) razvidno, da je geminata (ta je lahko pozneje poenostavljena v izglasju) v I(T)ed. ja-osnov v posameznih zgerm. jezikih (tudi v stari frizijščini) naknadno vpeljana po stranskosklonskih oblikah (prim. stfriz. net, stsaš. net, stang. nett < *natjan 'mreža'; ken, kunni, cynn < *kunjan 'rod'; bed, bed/beddi, bedd < *badjan 'postelja'). Dodatno podporo k takšni ugotovitvi prinaša stang. velelnik freme (k fremman 'podpirati') $<*$ fremi $<*$ fremj $<$ apokopa *fremje (in ne **fremm!). Razvoj je tako treba predvideti v tejle smeri: $*_{-} K-j a z / \tilde{a}>$ apokopa $*_{-} K-j>$ silabifikacija $*-K-i$. Glede na odsotnost oblik tipa **bett v stari visoki nemščini lahko ugotavljamo, da je bila geminata iz drugih sklonov v I(T)ed. uvedena že v končno razvojno stopnjo beti: zgerm. ${ }^{*}$ badj $>{ }^{*}$ bati $>{ }^{*}$ beti $\rightarrow$ stvn. betti (po Red bettes, Ded bettie ...), in sicer po delovanju apokope izglasnega $-i$ za težko sekvenco. Stanje v stari angleščini, stari frizijščini in stari saščini nasprotno kaže, da je do analoške uvedbe geminate prišlo v času pred apokopo in da je bil nato $-i\left(\mathrm{oz} . *_{-} i>-e\right) \mathrm{v}$ stari frizijščini in stari saščini lahko naknadno dodan na že apokopirane osnove (po tipu s težko korensko osnovo, npr. stfriz. erve 'dediščina' < *arb-ij-an, ende 'konec' < *andijaz): *badj $>*$ badi $\rightarrow *$ baddi (po stranskosklonski osnovi *baddj-) > stang./ stfriz./stsaš. bedd/bed > stsaš. beddi. Na velar izglasne lahke osnove v stari angleščini in stari frizijščini kažejo, da je moralo do zamenjave $* \gamma z$ z $g g$ priti že pred palatalizacijo, saj $* j\left(=* \gamma^{\prime}\right)$ ni bil v tvornem morfofonemskem razmerju $\mathrm{z} * g$ in bi bila morfemska meja tako zabrisana, torej ITed *uegjã $>*$ ui $\gamma i:$ Ded *uiggjæ ... $\rightarrow$ ITed *uiggi. Če upoštevamo relativnokronološko umestitev palatalizacije pred delovanje ijevskega preglasa, je treba apokopo - $i$ za težko sekvenco umestiti v čas po zaključeni palatalizaciji, saj preglas logično nastopi pred apokopo/sinkopo. Po takšnem poteku vpletenih glasovnih sprememb pričakujemo razvoj ITed *uiggi > *uig'g’i

${ }^{27}$ Sinkopa $i \mathrm{v}$ notranjem zaprtem zlogu je znotraj stare angleščine značilna le za zahodno saščino (prim. angl. sōéce d = zsaš. sēcp) (Hogg 1992: 269), medtem ko je v stari frizijščini splošna.

${ }^{28}$ Do identičnega procesa prihaja v pozni zahodni saščini, prim. sēhp (3. ed. sed. k sēéan 'iskati') (Campbell 1959: § 483). 
$>$ *uig'g', kar da stang. wic் (kot *hruүj $\rightarrow$ *hruggi > palatalizacija *hrug'g'i > preglas *hryg'g'i > apokopa *hryg'g'> asibilacija *hryžž 〈hrycg 'hrbet'). Vendar takšen potek dogodkov ne pojasnjuje starofrizijskega stanja.

Pri poskusu ustrezne razlage se je morda treba opreti na dejstvo, ki je pri preučevanju starofrizijskega gradiva najbolj vpadljivo, tj. popolna odsotnost oblik z asibiliranim velarom v izglasnem položaju. Pojav je širši, sistemski in zajema vse primere z etimološkim izglasnim *- ${ }_{-\bar{l}}$, ki je bil podvržen apokopi, prim. še benk

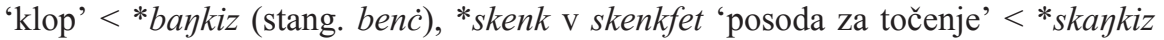
(stang. siencं 'čaša'), feng 'prijem, prijemanje' < *faygiz (stang. feng), sweng 'zalivanje' < *suang'iz, brēk (ITmn k brōk 'hlače') < *brōkiz (stang. brēc்), wrēk wrētse 'maščevanje' (stang. wrōè) $<* u r \bar{e} \bar{e}^{1} k \bar{l}$, sprēke (za pričakovano **sprēk kot wrēk) sprētse 'govor' (stang. $s p(r) \bar{x} \dot{c})<{ }^{*} s p r \bar{e} \bar{e}^{-1} k \bar{l}$. Možni razlagi takšnega stanja (v nasprotju s stanjem v stari angleščini) sta pravzaprav dve. Kot priča proces depalatalizacije v tipu stfriz. werkth, je bil prehod palataliziranih velarov v palatale lahko fonetično moten, saj so bili le-ti nedvomno občutljivi na novo glasovno okolje, $v$ katerem so se znašli po odpadu sledečega elementa. Na ta način lahko s splošno, tj. sistemsko restrikcijo asibilacije $\mathrm{v}$ popolnem izglasju pojasnimo vse zgornje primere: palatalizacija *eg'g'ju, *uig'g'i > apokopa eg'g'(j), *uig'g'> depalatalizacija *egg, *uigg (> stfriz. egg, wegk). Otrditev * $\left(k^{\prime}\right) k^{\prime}, *\left(g^{\prime}\right) g^{\prime}$ v stiku z $\emptyset$, tj. v premoru, je tipološko primerljiva z otrditvijo ob trku s soglasnikom. Depalatalizacije v primeru $* \gamma^{\prime}=* j$ ne pričakujemo, saj $* j$ ni nastopal $\mathrm{v}$ alofonski distribuciji $\mathrm{z} * \gamma$ (ta se tudi ne potrjuje, prim. stfriz. dei 'dan' in ne $* * d e c h<* d e \gamma$, kar je dodaten znak odsotnosti dejanske vmesne stopnje $*^{*}$ ’ v primeru palatalizacije $* \gamma<$ pgerm. ${ }^{*} g$ ). Druga razlaga se opira na ne povsem gotovo medsebojno relativnokronološko umestitev palatalizacije in ijevskega preglasa $v$ stari frizijščini. Na podlagi izpričanih primerov, kjer velar stoji v poziciji pred preglašenim samoglasnikom oziroma njegovim refleksom, lahko namreč sklepamo le na dejstvo, da je bila palatalizacija zaključena vsaj do časa razokroženja preglašenih pfriz. $* \overline{\bar{y}}<* \breve{\bar{u}}^{i}, * \breve{\bar{D}}<* \breve{\bar{o}}^{i}, * \bar{\infty}<* a u^{i},(* \breve{e}), * \bar{x}$ $<* a i^{i}$ v sprednje samoglasnike, saj jasnih znakov o občutljivosti velarov na zaokrožene, tj. labializirane, sprednje samoglasnike (ta tipološko sicer ni izključena) ni. ${ }^{29}$ Če nam to dovoljuje umestitev delovanja palatalizacije za proces ijevskega preglasa, jo lahko brez težav uvrstimo v čas med apokopo (ki logično sledi preglasu) in razokroženje sprednjih samoglasnikov, vendar zagotovo že v čas pred sinkopo, ${ }^{30} \mathrm{~s}$ čimer bi prav tako uspešno pojasnili odsotnost palatalov v apokopiranem izglasju: po sosledju 1. preglas, 2. apokopa $-i, 3$. palatalizacija bi iz analoško preoblikovanega ITed. *uegg-i dobili izpričano obliko *uegg/*uigg (stfriz. wegk =*wegg), pri čemer je ITed widze prodrl iz stranskosklonskih, Ded wegke $=*$ wegge pa iz krepkosklonskih oblik (enako Red reggis $=*$ hregges k hreg 'hrbet') oz. *ægg-ju > preglas *eggju > apokopa *egg. Pomembno je izpostaviti, da je čas odpada medglasnega

${ }^{29}$ Preteritne oblike glagolov dìtsa, sētsa niso ohranjene, vendar $\mathrm{v}$ teh primerih lahko pričakujemo razvoj relevantnih oblik tipa stang. drencte $(* d r æ y k-i-ð æ x) \mathrm{k}$ drencan 'potopiti' <*drayk-ij-anan oz. stfriz. skankte (k skentsa), torej **dīkte, **sēkte.

${ }^{30}$ Takšnih znakov, ki govorijo v prid takojšnjemu prehodu * $\gamma^{\prime}{ }^{*}{ }^{*} j\left(\right.$ saj $\left.\gamma^{\prime}=\gamma^{i}\right)$, je še več $(\mathrm{gl}$. dalje spodaj). 
-j- v Ied ženskih jō-osnov ( = ITmn jo-osnov srednjega spola $<*-i-e H_{2}: *-i-e-H_{2}$ ) težko določljiv, saj se nedvomno in brezizjemno potrjuje, a zanj pravzaprav ni bilo pogojev ne po zaključeni apokopi ne pred njo (sinkopa je mlajša od apokope!). Morda je po apokopi v tem tipu prišlo do absorpcije * $*_{-j}$ ali pa je bil njegov odpad sistemsko neregularen in je do njega prišlo že pred njo. Vsekakor tudi tu pričakujemo medsebojni vpliv palataliziranih in nepalataliziranih oblik, prisotnih znotraj ene in iste paradigme, tako Ied edze za pričakovano eg(g) po stranskosklonski osnovi in Ded egge, Dmn eggum za pričakovano **edze, **edzum po Ied (enako je palatal v dvojničnih oblikah Ied sprētse in wrētse za pričakovano **sprēk in wrēk tako kot izglasni $-e<*_{-j æ}<*_{-}-i \bar{o} m$ prodrl iz tožilnika ednine).

Občutljivost velarnega pripornika na sprednje samoglasnike v medglasju je nedvomno večja od občutljivosti obeh zapornikov, saj se $*_{j}=* *^{\prime}$ redno pojavlja tudi pred najnižjim sprednjim samoglasnikom: deis ${ }^{31}<*$ dejes $<*$ dæræs $<*$ dagas (Red k dei, riustr. $d \bar{\imath}$ 'dan') (stang. dæges), weis $<*$ uejes $<*$ ueyæs (Red k wei, riustr. $w \bar{l}$ 'pot') (stang. weges) ob hei 'um' <*heie <* $\chi u g i z$ (stang. hege), sī 'zmaga' $<*$ siyiz $<*$ segiz (stang. sige), leine 'laž' $\leq *$ lein $<*$ lejen $<*$ lyyin $<*$ luginō (stang. lygen), dreith $<*$ dræyip $<*$ dragipi (3. ed. sed. k draga 'vleči'), riustr. lìth $<*$ lijp $<$ *liyip <*ligjipi (stang. lig $p$, līp) (3. ed. sed. k lidza 'ležati'), leith $<*$ lærip $<*$ lagjipi (3. ed. sed. k ledza 'položiti'), weith <*uærip < *uagjipi (3. ed. sed. k wega 'tehtati' za pričakovano **wedza, prim. stang. we ċgan $<*$ uagjanan), breith $<*$ brejip $<*$ bregipi (3. ed. sed. k riustr. brīda 'potegniti, vleči'), slein $<*$ slejen $<*$ slarina(stang. slegen $<*$-ina- ob slæg gen $<*$-ana-) (pret. del. k slā 'zaklati'), drein $<*$ drejen $<*$ dræyina- (pret. del. k drega 'nositi'), tein $<*$ tejen $<*$ tøyin $<*$ togina- (pret. del. k tiā 'vleči'), leid <*læryida- <*lagiða- (pret. del. k ledza 'položiti'), leide < *læyidæ< < lagiðæ (3. ed. pret. k ledza), seid <*sæyida- (pret. del. k sedza 'reči'),

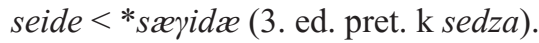

\section{$3 \quad$ Palatalizacija v izglasju}

Palatalizacija v izglasju je lahko izključno progresivna, pri čemer gre torej za občutljivost velara na predhodnji sprednji samoglasnik. Kot nedvomno kaže primerjava stfriz. dīk 'jarek' $<*$ dìkaz, -līk <*-lìka-, tserke $<* k$ 'erikæ, thing $<*$ pingaz, dei $<$ $*$ dæy $<*$ dagaz, Dmn degum ${ }^{32}<*$ dagomiz, Imn degar $<*$ dagōzes, wei $<*$ uey $<$

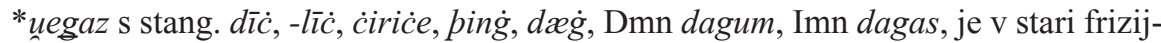
ščini progresivni palatalizaciji podvržen le $* \gamma$, in sicer izključno, če mu neposredno ne sledi zadnji samoglasnik (stfriz. degum, stang. daggum toda íirịce).

${ }^{31} \mathrm{~V}$ stari frizijščini redovito prihaja do sinkope/apokope medglasnega -e-oz. izglasnega -e v položaju za *j $=*{ }^{\prime}$ ', prim. fleil 'cepec (za žito)' <*flæjel $\leftarrow$ lat. flagellum, hreil 'obleka'

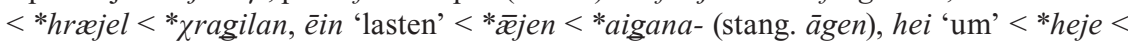
$*$ hyji $<*$ ugi.

${ }^{32} \mathrm{Z}$ analoško razširitvijo $*_{\mathscr{C}}>$ stfriz. $e \mathrm{v}$ vse sklone (prim. stang. Imn dagas, Ded dagum po pričakovani vokalnokvalitetni restituciji (ang. »restoration«) pred zadnjim samoglasnikom sledečega zloga). 
Do palatalizacije $* \gamma$ enako kot $\mathrm{v}$ stari angleščini prihaja tudi $\mathrm{v}$ položaju med sprednjim samoglasnikom in sledečim rezonantom, ki je po zgodnji apokopi stal v izglasju: seil 'jadro' < *serl < *seglan (stang. segl), wein 'voz' < *uær

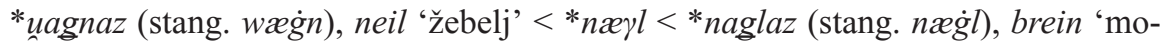

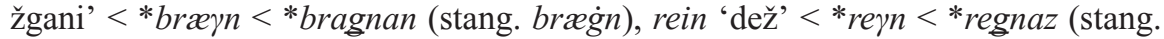
reg்n). Čeprav so z anaptikso oz. silabifikacijo nastale oblike tipa stang. segel, segil, næg்el, bræg்en $\mathrm{v}$ stari frizijščini popolnoma odsotne, moramo na podlagi stfriz. fugel [fuүəl/furl] 'ptič' < *fuglaz (stang. fugol, fugel) ${ }^{33}$ sklepati, da so nekdaj bile prisotne, vendar so jih v celoti nadomestile enozložne oblike, ki so prodrle iz stranskih sklonov, kjer sta bila $* \gamma$ in sledeči resonant $\mathrm{v}$ heterosilabičnem položaju. $\mathrm{V}$ primerjavi z *ækk(e)r 'polje' <*akkraz, kjer se je podedovana oblika *ækkr po zgodnji apokopi izglasja lahko realizirala le kot *ækker/ækkkrr (preko anaptikse) ali * $æ k k_{\text {r }}$ (preko ozloženja), je lahko resonant v tipu *næjl (stfriz. neil, stang. næg்l) $\leftarrow *_{\text {næjlles }}^{*}$ *næjlæ ... ostal v tavtosilabičnem položaju s predhodnim *j, saj je to dopuščala struktura zloga s stopničastim upadanjem zvočnosti v kodi: soglasnik + samoglasnik + polglasnik + resonant $(* K V U R \#)$ proti $* K V K R$ (npr. *ækk $\left.{ }^{*}\right)>$ $* K V K \$ R \#$. Jasen odgovor na vprašanje, ali je palatalizacijo $* \gamma$, ki se je v tem tipu nahajal v izglasju besednega zloga, povzročil prvotni sprednji anaptiktični samoglasnik in gre za medglasno regresivno palatalizacijo ali gre pravzaprav za izglasno progresivno palatalizacijo, podajo zgledi kot ruistr. brīda 'potegniti, vleči' < brejda $<*$ breydan < *bregðanan (stang. bregdan), leina 'zavrniti veljavnost zaprisege' (= *lēina) < *lōjnan < *laugnijanan (stang. lìegnan 'zanikati'), kjer do anaptikse ni nikdar prišlo.

\section{$4 \quad$ Zaključek}

Ker sufiksalni del pridevnikov na -ich ${ }^{34}(-i g-)$ nikdar ne izkazuje palatalizacije, prim. blōdich 'krvav' < *blōdæy (stang. blödig > srang. blödi), letheges <*lepæræs $<*$ lipagas (Red k lethich 'prazen'), prav tako pa je ta odsotna v thritich '30' <*-ti (stang. prītig $>$ srang. pritti) in hunige $<*$ hunæ $æ x<*$ *unagai (Ded k hunich 'med', stang. hunæg $\dot{g}$ ), kar je pravzaprav presenetljivo, moramo sklepati, da je palatalizacijo pogojeval dodaten dejavnik, in sicer oddaljenost kombinacije velara in sprednjega samoglasnika od naglašenega zloga. Glede na razporeditev palataliziranih in nepalataliziranih oblik z upoštevanjem vseh opisanih analoških procesov, ki so prvotno stanje deloma ali v celoti zameglili, lahko torej ugotavljamo, da prafrizijska palatalizacija velarov nikakor ni bila enovit proces ne po času niti po obsegu delovanja, temveč se je začela na besednem vzglasju, kjer je bil njen obseg največji, saj je do palatalizacije prišlo v vseh relevantnih pozicijah (tj. $\left.* k,{ }^{*} g / \ldots \bar{l}, i, \bar{e}, e, \bar{x}, \mathfrak{x}\right)$

\footnotetext{
${ }^{33}$ Prav slednja oblika, v kateri je zveneči velarni pripornik ohranjen, ne dopušča razlage pojava z lenizacijo $\gamma>j$ (v tem primeru bi namreč pričakovali stfriz. **fuil, stang. **fug $(e) l)$, kar bi bilo tipološko sicer mogoče, prim. pkelt. *brugnos $>*$ bruүn $>*$ brujn $>$ kimr. brwyn 'žalost'.

${ }^{34} \mathrm{Z}$ izglasnim onezvenečenjem ${ }^{*}-\gamma>{ }^{*}-\chi\langle\mathrm{ch}\rangle$.
} 
- in se je nato širila proti medglasju, tako da je zajela izglasje prvega naglašenega zloga in vzglasje drugega zloga ${ }^{35}$ (morda šele v času po zaključeni apokopi?), vendar $\mathrm{v}$ že zmanjšanem obsegu v primeru $* k$ in $* g$, pri čemer je občutljivost na predhodni sprednji samoglasnik, tj. palatalizacija po progresivni asimilaciji, prizadela le $* \gamma(\mathrm{v}$ primeru $* \gamma$ tudi ni spremembe v obsegu medglasne palatalizacije, kar je razložljivo z večjo občutljivostjo $* \gamma$ na sosednji sprednji samoglasnik). Dalje od vzglasja drugega zloga proces očitno ni segel. Iz opisanega sistema odstopa le Ded (<Med) kenindze $<* k u n i \eta g \bar{l}$, kjer je palatalizacija izpričana na vzglasju tretjega zloga. V luči podanih ugotovitev je oblika najverjetneje analoškega nastanka po preostalih dvozložnih dajalnikih (tj. prvotnih mestnikih) ednine tipa thindze. ${ }^{36}$

\section{Krajšave}

ang. = sodobno angleško; angl. = anglijsko; got. = gotsko; kimr. = kimrijsko; lat. = latinsko; nth. = northumbrijsko; pfriz. = prafrizijsko; pgerm. = pragermansko; pkelt. $=$ prakeltsko; riustr. $=$ riustrinškofrizijsko; sat. $=$ saterlandsko; sfriz. $=$ severnofrizijsko; smger. = severnomorskogermansko; srang. = srednjeangleško; stang. = staroangleško; stfrank. $=$ starofrankovsko; stfriz. $=$ starofrizijsko; stisl. = staroislandsko; stsaš. = starosaško; stvn. = starovisokonemško; zfriz. = sodobno zahodnofrizijsko; zgerm. = zahodnogermansko; zsaš. = zahodnosaško.

\section{Viri in literatura}

AFG $=$ Willem Lodewijk van Helten, Altostfriesische Grammatik, Leeuwarden, 1890. 〈http://www.wumkes.nl, dostop 23. 9. 2011.〉

AFW = Dietrich Hofmann - Anne Tjerk Popkema, Altfriesisches Handwörterbuch, Heidelberg: Universitätsverlag Winter, 2008.

Braune 1987 = Wilhelm Braune - Hans Eggers, Althochdeutsche Grammatik, Tübingen: Max Niemeyer Verlag, ${ }^{4} 1987\left({ }^{1} 1886\right)$.

Bremmer 2009 = Rolf Hendrik Bremmer Jr., An Introduction to Old Frisian, Amsterdam - Philadelphia: John Benjamins Publishing Company, 2009.

${ }^{35}$ Medglasna palatalizacija je nedvomno povezana s splošno šibitvijo samoglasnikov v nenaglašenih zlogih, ki se kot najvidnejša odraža v sinkopi. Tipološko primerljivo je staroirsko stanje, kjer do t. i. tretje palatalizacije prihaja izključno pred reduciranim sprednjim polglasnikom, ki je bil nato sinkopiran (npr. stirs. Coithirche [kov'r' $\chi$ 'e]

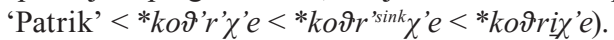

${ }^{36}$ Odsotnost palatalizacije v rīke 'kraljestvo' < *rīkijan (stang. rīèe) in Ded rīke < *rīkijæ ni pričakovana, saj v tem tipu ni nikdar prišlo do apokope izglasnega $*_{-}-\bar{\imath} * *_{i j}$ (kot ende 'konec' $<* æ x d \bar{\imath}<* a n d-i j-a z)$ in je bil v času nastopa palatalizacije * $k$ zagotovo palatali-

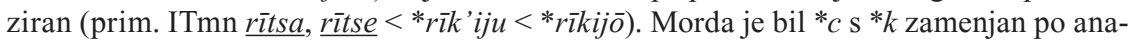
logiji z oblikami, kjer se je samostalnik *rīkijan pojavljal kot drugi del kompozita, npr. v pogostem keningrīke 'kraljestvo'. 
Campbell 1959 = Alistair Campbell, Old English Grammar, Oxford: Clarendon Press, 1959.

de Vaan 2011 = Michiel de Vaan, West-Germanic *ai in Frisian, v: Thi timit lof: Festschrift für Arend Quak zum 65. Geburtstag, ur. Guus Kroonen idr., Amsterdam - New York: Rodopi, 2011 (Amsterdamer Beiträge zur älteren Germanistik 67), 301-314.

Hock 1991 = Hans Henrich Hock, Principles of Historical Linguistics, Berlin New York: Mouton de Gruyter, ${ }^{2} 1991$ ( $\left.{ }^{1} 1986\right)$.

Hoekstra 2001 = Jarich Freark Hoekstra, An Outline History of West Frisian, v: Handbuch des Friesischen $=$ Handbook of Frisian Studies, ur. Horst Heider Munske, Tübingen: Max Niemeyer Verlag, 2001, 722-734.

Hogg 1979 = Richard Milne Hogg, Old English Palatalization, Transactions of the Philological Society (1979), 89-113.

Hogg 1992 = Richard Milne Hogg, A Grammar of Old English I: Phonology, Oxford - Cambridge (USA): Blackwell, 1992.

Krogh 1996 = Steffen Krogh, Die Stellung des Altsächsischen im Rahmen der germanischen Sprachen, Göttingen: Vandenhoeck und Ruprecht, 1996 (Studien zum Althochdeutschen 29).

MEG = Joseph Wright - Elizabeth Mary Wright, An Elementary Middle English Grammar, Oxford: Oxford University Press, ${ }^{2} 1928\left({ }^{1} 1923\right)$.

Stiles 1995 = Patrick Stiles, Remarks on the 'Anglo-Frisian' thesis, v: Friesische Studien II, ur. V. F. Faltings - A. G. H. Walker - O. Wilts, Odense: Odense University Press, 1995, 177-220.

\section{Remarks on the palatalization of velars in Old Frisian}

\section{Summary}

Early Proto-Frisian $* k(<$ Proto-Germanic $* k),{ }^{*} g\left(<\right.$ PGmc. ${ }^{*} g$ after nasal, West Germanic geminated $* g g<$ PGmc. $\left.{ }^{*} g / \ldots *_{j}\right)$ and $* \gamma\left(<\right.$ PGmc. $\left.{ }^{*} g\right)$ were subject to palatalization, the result of which were palatal $*_{c}, *_{3}$ respectively (with further development into the biphonemic sequences $/$ ts $/$ and $/ \mathrm{d} / /)$ and merger with old $* j$ $<$ PGmc. $* j$ in the case of palatalized $* \gamma$. Based on the evidence of Old Frisian dei 'day' < *dæy vs. wegk 'horse' < *uig'g' < *uig'g' $i$ and werkth 'works' < syncopated *uyrkp<*uyrk'ip vs. breith 'draws' < sync. *brejp $<*$ brejip $<*$ bre $\mathrm{nip}$, this merger must have been simultantaneous, so that $* \gamma^{\prime}=* j$.

From the distributional pattern of forms with palatalized and unpalatalized reflexes, it must be inferred that PFris. palatalization was a gradual process, which began in anlaut, where it occurred in front of all front vowels as they existed after PGmc. $* \bar{e}^{l}>$ PFris. $* \bar{x}$ and the subsequent fronting of PGmc. $* a>$ PFris. $* x$, but before the unrounding of umlauted vowels (OFris. tserl 'man', tsetel 'cauldron', tsivia

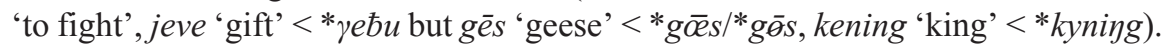
From there it progressed towards the anlaut of the second syllable, where its effect was weakened so that it only affected $* k$ and $* g$ if followed by $* j$ or $* \bar{l}$ (i.e., the most 
- conducive environments to palatalization). In the case of $* \gamma$, however, there is no [त similar restriction (cf. deies $<*$ dæræes); furthermore, due to the extreme sensitivity $N$ of the voiced velar fricative to the adjacent front segment it is additionally affected

- by progressive palatalization in auslaut of the first syllable (OFris. dei $<* d æ \gamma$, neil $\mathbb{A} \quad$ 'nail' $<*$ naglaz $\leftarrow$ with the consonantal value of the resonant introduced from the oblique cases, breida 'to draw' < *breydan). On the evidence of blodich 'bloody', letheges (Gsg of lethich 'empty'), etc., it must be concluded that the process of palatalization did not reach beyond the immediate inlaut.

This state of affairs is partly blurred by analogical (mostly interparadigmatically motivated) processes of the type kerva 'to carve' for **tserva $<* k e r \hbar a n a n$ $\leftarrow$ past ptcp. korven, past ptcp. breken 'broken' (alongside bretsen) $\leftarrow$ inf. breka, or allomorphy; e.g., past ptcp. gendzen 'gone' <* gaygina- alongside gangen < *-ana-. The coexistence of palatalized and unpalatalized forms such as rētsa rēka 'reach', brendza brenga 'bring', etc. must be due to analogical reintroduction of the unpalatalized velar into the infinitive from the 2 nd and $3 \mathrm{rd}$ person singular of the present indicative, where depalatalization was regular in front of a consonant (palatalization *uyrk'ip 'works'> syncope *uyrk' $b>$ depalatalization *uyrkp). The complete absence of palatals in absolute auslaut (wegk 'horse', egg 'edge', benk 'bench', brēk 'breeches') can be accounted for either on grounds of relative chronology, so that apocope antedates palatalization (*eggju, *uiggi > apocope *egg, *uigg > OFris. egg, wegk; in this case it must be assumed that velars would not have been sensitive to front rounded vowels that emerged as a result of $i$-umlaut), or by a general tendency to depalatalize all palatals that stood in absolute auslaut after the operation of apocope (*agjo 'edge', *uegjan 'horse' > palatalization *eg'g'ju, *uig'g'i > apocope eg'g'(j), *uig'g'> depalatalization *egg, *uigg > OFris. egg, wegk). 